\title{
Delaware Method Improvement for the Shell and Tubes Heat Exchanger Design
}

\author{
Miguel Toledo-Velázquez1, Pedro Quinto-Diez¹, Juan C. Alzelmetti-Zaragoza², \\ Sergio R. Galvan ${ }^{3}$, Juan Abugaber-Francis ${ }^{1}$, Arturo Reyes-León' \\ ${ }^{1}$ Applied Thermal and Hydraulic Engineering Laboratory SEPI-ESIME-IPN Professional Unit "Adolfo Lopez \\ Mateos", México DF, México \\ ${ }^{2}$ Faculty of Mechanical Electrical Engineering, Universidad Veracruzana, Veracruz, México \\ ${ }^{3}$ Faculty of Mechanical Engineering, Universidad Michoacana de Sán Nicolas de Hidalgo, Edifice H, University \\ City, Santiago Tapia 403, Col. Centro, Morelia, Michoacán, México \\ Email: mtv49@yahoo.com, arthuro reyes@yahoo.com.mx
}

Received 30 April 2013; revised 30 May 2013; accepted 8 June 2013

Copyright (C) 2014 by authors and Scientific Research Publishing Inc.

This work is licensed under the Creative Commons Attribution International License (CC BY).

http://creativecommons.org/licenses/by/4.0/

(c) (i) Open Access

\begin{abstract}
In this paper the Delaware Method published in 1963 is analyzed and upgraded with using correction factors which take into account the undesirable currents of the mean flow. However, this method presents graphically these correction factors which imply an impediment to fulfill the software calculations. Thus, the equations corresponding to the correction factor equations and a Fortran 77 numerical program were established. This system is given to explore different design alternatives in order to find the optimal solution to each proposed problem. The results of this work was a simple software that can perform calculations with the introduction of parameters depending only on the geometry of the heat exchanger, i.e., geometry, temperature and fluid characteristics eliminating the human errors and increasing the calculations speed and accuracy.
\end{abstract}

\section{Keywords}

Delaware Method; Flow; Correction Factor; Heat Exchanger

\section{Introduction}

The method is established in the heat transfer analysis and in the pressure losses of the fluid which flows through the shell side [1] [2].

In order to complete the heat exchanger analysis, it is essential to consider the different currents generated by the shell side flow, as is shown in Figure 1. This figure has been modified by Palen and Taborek [3] [4] in regard to 
the original version proposed by Tinker [5]. Here five different streams are identified side of the shell. The current $\mathrm{B}$ is known as the mean mixed flow and flows through the mixed flow section and the window section of the heat exchanger. This is the ideal current flowing in the shell side of a heat exchanger.

Besides of flow B, there are four more flows which are present due to the free spaces and cavities between the shell and the deflectors and they provoke a modification of the current B performance.

The different leakages and recirculation currents influence the heat flux transfer in two ways:

1) Reduce the current $B$ resulting in a drop of the heat transfer global coefficient.

2) Modify the shell-side temperature distribution.

The Delaware method considers these effects as correction factors in the heat transfer coefficient and the loss pressure calculations.

The basic equations of the heat exchangers thermal design are:

$$
\begin{gathered}
Q=U_{d c} A F T_{m l c} \\
U_{d c}=\frac{1}{\frac{1}{h_{i o}}+\frac{1}{h_{c c}}+R_{d}+\frac{\mathrm{e}_{\mathrm{t}}}{k}}
\end{gathered}
$$

In the Equation (2), $h_{c c}$ is the fluid convection coefficient flowing in the shell and it is obtained by Equation (3). In this equation the correction factors are included, the correction factors $J_{i}, J_{c}, J_{l}, J_{b}, J_{r}, J_{r}^{*}$ and $J_{s}$, which consider the different currents shown in Figure 1.

$$
h_{c c}=J_{i} C p_{c}\left(\frac{W_{c}}{S_{m}}\right)\left(\frac{k_{c}}{C p_{c} \mu_{c}}\right)^{2 / 3}\left(\frac{\mu_{c}}{\mu_{w c}}\right)^{0.14} J_{c} J_{l} J_{b} J_{r} J_{s}
$$

For the hydraulic design is required to determine the fluid pressure loss through the shell side and it must be included the correction factors $f_{i}, R_{b}, R_{l}$ and $R_{s}$. The corresponding calculation is made using the next equation:

$$
\Delta P_{c}=\left\{\left(N_{b}-1\right)\left[\frac{4 f_{i} W_{c}^{2} N_{c}}{2 g \rho_{c} S_{m}^{2}}\left(\frac{\mu_{w c}}{\mu_{c}}\right)^{0.14}\right] R_{b} R_{l}+2 \Delta P_{b, i}\left(1+\frac{N_{c w}}{N_{c}}\right) R_{b} R_{s}+N_{b} \Delta P_{w, i} R_{l}\right\}
$$

It is observed that the principal problem using the Delaware Method is the determination of the eleven correction factors of which nine are obtained graphically. In the next section, the nine correction factors will be presented analytically. The original version only presents analytically the $J_{s}$ and $R_{s}$ correction factors.

\section{Shell Side Correction Factor Equations}

According to the Delaware method, after the geometrical parameters computations, the heat transfer and loss pressure are estimated considering the correction factors. This special case will be shown in the next section by using the appropriate Equations [6]-[8].

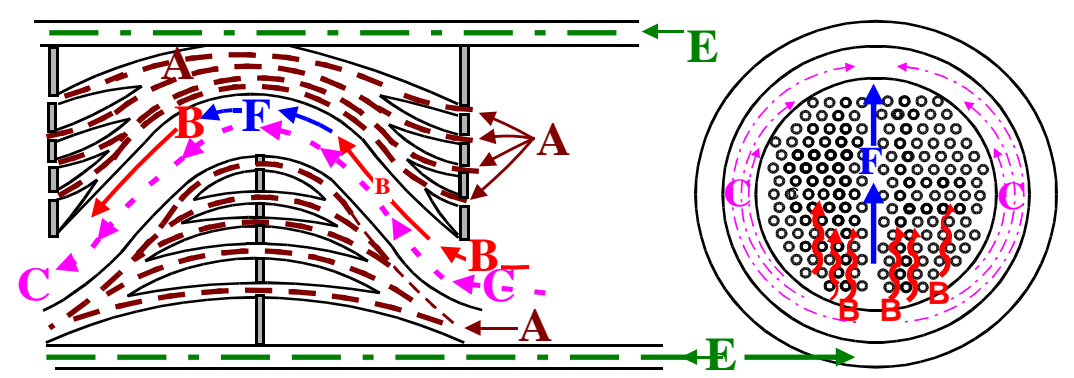

Figure 1. Ideal design of the currents flowing in the shell side. A. Currents flowing through the free spaces between tubes and baffles; B. Mean current flow; C. Recirculation current; D. Leakage current between shells and deflectors; E. Recirculation current in the past partition. 


\subsection{Correction Factor $J_{i}$}

This factor depends on the Reynolds Number $\operatorname{Re}_{c}$ and the tube arrangement as is established in the next equation:

$$
J_{i}=\exp \left[\mathrm{A}+\mathrm{B} \ln \left(\mathrm{Re}_{c}\right)+\mathrm{C} \ln \left(\mathrm{Re}_{c}\right)^{2}+\mathrm{D} \ln \left(\mathrm{Re}_{c}\right)^{3}+\mathrm{E} \ln \left(\mathrm{Re}_{c}\right)^{4}+F \ln \left(\mathrm{Re}_{c}\right)^{5}\right] a
$$

This equation is applied to the different arrangement tube types: triangular, square, and rhombic. For each case, the constant are presented in Table 1 . It was determined $4 \%$ as that the maximum error between the equations and the graphic presentation.

\subsection{Correction Factor $J_{c}$ by the Baffle Configuration Effect}

The deflector geometry and especially the window cross-section shape provoke currents where the effects are considered in the correction factor $J_{c}$. This factor is determined in a mathematical way as following:

$$
J_{c}=\mathrm{A}+\mathrm{B} F_{c}+\mathrm{CF}_{c}^{2}+\mathrm{DF}_{c}^{3}+\mathrm{EF}_{c}^{4}
$$

The values of each constant are presented in Table 2. Comparing the graphics obtained by Equation (6) and the original one, the maximum error established is $5 \%$.

\subsection{Correction Factor by Baffle Leakages Effect, $J_{I}$}

The fluid that does not exchange heat owing to the leakage through the gap formed by the tubes and the baffles as well as through the shell and baffle is considered in the correction factor $J_{l}$. This factor is obtained using the Equation (7) where:

$$
S_{1}=S_{s b} /\left(S_{s b}+S_{t b}\right) \text { and } S_{2}=\left(S_{s b}+S_{t b}\right) / S_{m}
$$

The constants required by this equation are available in Table 3. Comparing the original graph against that one getting by Equation (7), the maximum error is $2 \%$.

$$
\begin{aligned}
J_{l}= & {\left[\mathrm{A}+\mathrm{B}\left(S_{1}\right)+\mathrm{C}\left(S_{1}\right)^{2}+\mathrm{D}\left(S_{1}\right)^{3}\right]+\left[\mathrm{E}+\mathrm{F}\left(S_{1}\right)+\mathrm{G}\left(S_{1}\right)^{2}+\mathrm{H}\left(S_{1}\right)^{3}\right]\left(S_{2}\right) } \\
& +\left[\mathrm{I}+\mathrm{J}\left(S_{1}\right)+\mathrm{K}\left(S_{1}\right)^{2}+\mathrm{L}\left(S_{1}\right)^{3}\right]\left(S_{2}\right)^{2}+\left[\mathrm{M}+\mathrm{N}\left(S_{1}\right)+\mathrm{O}\left(S_{1}\right)^{2}+\mathrm{P}\left(S_{1}\right)^{3}\right]\left(S_{2}\right)^{3}
\end{aligned}
$$

Table 1. Constants for the equation for the correction factor $J_{i}$.

\begin{tabular}{|c|c|c|c|c|c|c|c|c|}
\hline Values of $S_{2}$ & A & B & $\mathrm{C}$ & $\mathrm{D}$ & $\mathrm{E}$ & $\mathrm{F}$ & G & $\mathrm{H}$ \\
\hline 0 to 0.1 & 1 & 0 & 0 & 0 & -2.5903333 & -4.8677761 & 8.773331 & -7.0222218 \\
\hline 0.1 to 0.7 & 0.90063003 & -0.0389402 & 0.1363475 & 0.05531749 & -0.4299145 & -1.0949101 & 1.4689544 & 0.7341744 \\
\hline Values of $S_{2}$ & I & $\mathrm{J}$ & $\mathrm{K}$ & $\mathrm{L}$ & M & $\mathrm{N}$ & $\mathrm{O}$ & $\mathrm{P}$ \\
\hline 0 to 0.1 & 15.8742857 & 50.8190476 & -133.48571 & 106.666666 & -39.6381 & -168.31699 & 486.093325 & -391.10933 \\
\hline 0.1 to 0.7 & -0.0567309 & 1.72685112 & -4.2124254 & 2.4290305 & 0.04115536 & 1.3220234 & 3.32880672 & -1.99187 \\
\hline
\end{tabular}

\begin{tabular}{ccccccc}
\hline Arrangement & A & B & C & D & E & -0.000937714 \\
\hline Triangular & 0.627615 & -0.69064 & -0.0507472 & 0.0141049 & $1.7683 \times 10^{-5}$ \\
Square & 0.374177 & -0.671577 & -0.0784051 & 0.02507191 & -0.00224983 & 0.0000673254 \\
Rhombic & -0.273166 & -0.472896 & -0.109701 & 0.023299 & -0.00145983 & 0.0000242675 \\
\hline
\end{tabular}

Table 2. Constants for the equation for the correction factor $J_{c}$.

\begin{tabular}{cccccc}
\hline For values of $F_{c}$ between & A & B & C & D & -0.295959596 \\
\hline 0 and 0.9 & 0.533574545 & 0.69059596 & 0.290909091 & 0 \\
0.9 and 1 & -27.84837787 & 152.5274893 & -301.9699773 & 265.12743360 & -86.76640715 \\
\hline
\end{tabular}

Table 3. Constants for the equation for the correction factor $J_{l}$. 


\subsection{Correction Factor by Recirculation Flow Effect, $J_{b}$}

The recirculation currents do not exchange heat through the tubes and this issue is considered by the correction factor $J_{b}$. This factor is computed by Equation (8) which is based on $F_{s b p}$. The constant of the Equation $N_{2}=$ $N_{s s} / N_{c}$ are defined in Table 4 in terms of $\mathrm{Re}_{c}$.

$$
\begin{aligned}
J_{b}= & {\left[\mathrm{A}+\mathrm{B}\left(N_{2}\right)+\mathrm{C}\left(N_{2}\right)^{2}+\mathrm{D}\left(N_{2}\right)^{3}+\mathrm{E}\left(N_{2}\right)^{4}\right]+\left[\mathrm{F}+\mathrm{G}\left(N_{2}\right)+\mathrm{H}\left(N_{2}\right)^{2}+\mathrm{I}\left(N_{2}\right)^{3}+\mathrm{J}\left(N_{2}\right)^{4}\right] F_{s b p} } \\
& +\left[\mathrm{K}+\mathrm{L}\left(N_{2}\right)+\mathrm{M}\left(N_{2}\right)^{2}+\mathrm{N}\left(N_{2}\right)^{3}+\tilde{\mathrm{N}}\left(N_{2}\right)^{4}\right] F_{s b p}^{2}+\left[\mathrm{O}+\mathrm{P}\left(N_{2}\right)+\mathrm{Q}\left(N_{2}\right)^{2}+\mathrm{R}\left(N_{2}\right)^{3}+\mathrm{S}\left(N_{2}\right)^{4}\right] F_{s b p}^{3} \\
& +\left[\mathrm{T}+\mathrm{U}\left(N_{2}\right)+\mathrm{V}\left(N_{2}\right)^{2}+\mathrm{W}\left(N_{2}\right)^{3}+\mathrm{X}\left(N_{2}\right)^{4}\right] F_{s b p}^{4}
\end{aligned}
$$

A maximum error of $1.3 \%$ is result of comparing the original graph against that one obtained by Equation (8).

\subsection{Correction Factor by Adverse Temperature Gradient $J_{r}$}

This factor has the value of 1 if $\operatorname{Re}_{c} \geq 100$. When $\operatorname{Re}_{c}$ fluctuation is between 0 and 100 , the next criterion is used:

1) If $\operatorname{Re}_{c} \leq 20, J_{r}$ will acquire the same value as $J_{r}^{*}$ using the Equation (9), and knowing that $N_{b}$ and $N_{1}=N_{c}$ $+N_{c w}$ are constants which are shown in Table 5.

$$
\begin{aligned}
J_{r}^{*}= & {\left[\mathrm{A}+\mathrm{B}\left(N_{1}\right)+\mathrm{C}\left(N_{1}\right)^{2}+\mathrm{D}\left(N_{1}\right)^{3}+\mathrm{E}\left(N_{1}\right)^{4}\right]+\left[\mathrm{F}+\mathrm{G}\left(N_{1}\right)+\mathrm{H}\left(N_{1}\right)^{2}+\mathrm{I}\left(N_{1}\right)^{3}+\mathrm{J}\left(N_{1}\right)^{4}\right] N_{b} } \\
& +\left[\mathrm{K}+\mathrm{L}\left(N_{1}\right)+\mathrm{M}\left(N_{1}\right)^{2}+\mathrm{N}\left(N_{1}\right)^{3}+\tilde{\mathrm{N}}\left(N_{1}\right)^{4}\right] N_{b}^{2}+\left[\mathrm{O}+\mathrm{P}\left(N_{1}\right)+\mathrm{Q}\left(N_{1}\right)^{2}+\mathrm{R}\left(N_{1}\right)^{3}+\mathrm{S}\left(N_{1}\right)^{4}\right] N_{b}^{3} \\
& +\left[\mathrm{T}+\mathrm{U}\left(N_{1}\right)+\mathrm{V}\left(N_{1}\right)^{2}+\mathrm{W}\left(N_{1}\right)^{3}+\mathrm{X}\left(N_{1}\right)^{4}\right] N_{b}^{4}
\end{aligned}
$$

\begin{tabular}{|c|c|c|c|c|c|c|c|c|c|}
\hline For & A & B & C & D & E & $\mathrm{F}$ & G & $\mathrm{H}$ & I \\
\hline $\operatorname{Re}_{c}>100$ & 0.99939474 & 0.01085613 & -0.0171267 & -0.1003071 & 0.19198207 & -1.2394301 & 13.4729632 & -85.593388 & 252.064457 \\
\hline $\mathrm{Re}_{c}<100$ & 0.9991889 & 0.02071706 & -0.185339 & 0.59250929 & -0.5964414 & -1.3564474 & 16.400326 & -116.51387 & 362.367998 \\
\hline For & $\mathrm{J}$ & $\mathrm{K}$ & L & M & $\mathrm{N}$ & $\tilde{\mathrm{N}}$ & $\mathrm{O}$ & $\mathrm{P}$ & Q \\
\hline $\operatorname{Re}_{c}>100$ & -249.7121 & 0.74529366 & -9.5329177 & 82.1849019 & -321.67178 & 378.959635 & -0.3575412 & 3.12005087 & -71.95138 \\
\hline $\operatorname{Re}_{c}<100$ & -368.18466 & 1.18264455 & -19.614535 & 140.62959 & -451.59784 & 478.689065 & -1.1031648 & 16.9758369 & -113.6298 \\
\hline For & $\mathrm{R}$ & $\mathrm{S}$ & $\mathrm{T}$ & U & $\mathrm{V}$ & W & $\mathrm{X}$ & & \\
\hline $\operatorname{Re}_{c}>100$ & 422.592705 & -576.65103 & 0.20001675 & -3.866875 & 70.1962129 & -363.1866875 & 473.343386 & & \\
\hline $\mathrm{Re}_{c}<100$ & 396.869404 & -457.40996 & 0.59140536 & -8.7366322 & 56.8613935 & -210.10305 & 253.214998 & & \\
\hline
\end{tabular}

\begin{tabular}{|c|c|c|c|c|c|c|c|c|}
\hline A & B & $\mathrm{C}$ & $\mathrm{D}$ & $\mathrm{E}$ & $\mathrm{F}$ & G & $\mathrm{H}$ & I \\
\hline 1.11286866 & -0.0444079 & 0.0019872 & $-4.324 \times 10^{-5}$ & $3.4787 \times 10^{-7}$ & -0.0289065 & $2.241 \times 10^{-4}$ & $1.5142 \times 10^{-6}$ & $9.5563 \times 10^{-8}$ \\
\hline $\mathrm{J}$ & K & $\mathrm{L}$ & M & $\mathrm{N}$ & $\tilde{\mathrm{N}}$ & $\mathrm{O}$ & $\mathrm{P}$ & $\mathrm{Q}$ \\
\hline$-3.11 \times 10^{-9}$ & 0.0008806 & $2.8301 \times 10^{-5}$ & $-2.088 \times 10^{-6}$ & $3.4527 \times 10^{-8}$ & $-9.296 \times 10^{-11}$ & $-1.363 \times 10^{-5}$ & $-9.749 \times 10^{-7}$ & $5.9493 \times 10^{-8}$ \\
\hline $\mathrm{R}$ & S & $\mathrm{T}$ & $\mathrm{U}$ & V & $\mathrm{W}$ & $\mathrm{X}$ & & \\
\hline$-8.947 \times 10^{-10}$ & $1.618 \times 10^{-12}$ & $8.3072 \times 10^{-8}$ & $8.7699 \times 10^{-9}$ & $-4.727 \times 10^{-10}$ & $5.7282 \times 10^{-12}$ & $8.9289 \times 10^{-15}$ & & \\
\hline
\end{tabular}

A maximum error of $1.9 \%$ is result of comparing the original graph against that one obtained by Equation (8).

2) If $20 \leq \operatorname{Re}_{c} \leq 100, J_{r}$ is computed by Equation (10) which depends on $J_{r}^{*}, \operatorname{Re}_{c}$ and Table 6 constants.

Table 4. Constants for the equation for the correction factor $J_{b}$.

Table 5. Constants for the equation for the correction factor $J_{r}^{*}$.

Table 6. Constants for the equation for correction factor $J_{r}$.

\begin{tabular}{ccccccccccc}
\hline $\mathrm{A}$ & $\mathrm{B}$ & $\mathrm{C}$ & $\mathrm{D}$ & $\mathrm{E}$ & $\mathrm{F}$ & $\mathrm{G}$ \\
\hline-0.2477376 & 0.0129611 & $-1.127 \times 10^{-5}$ & $6.5427 \times 10^{-8}$ & 1.26556042 & -0.0129666 & $2.5357 \times 10^{-6}$ & $1.5481 \times 10^{-8}$ \\
\hline $\mathrm{I}$ & $\mathrm{J}$ & $\mathrm{K}$ & $\mathrm{L}$ & $\mathrm{M}$ & $\mathrm{N}$ & $\mathrm{O}$ \\
\hline-0.0481867 & $2.2364 \times 10^{-4}$ & $1.6928 \times 10^{-5}$ & $-1.708 \times 10^{-7}$ & 0.03112154 & $-2.758 \times 10^{-4}$ & $-6.979 \times 10^{-6}$ & $8.3062 \times 10^{-8}$ \\
\hline
\end{tabular}




$$
\begin{aligned}
J_{r}= & \left(A+B \mathrm{Re}_{c}+C \mathrm{Re}_{c}^{2}+D \mathrm{Re}_{c}^{3}\right)+\left(E+F \mathrm{Re}_{c}+G \mathrm{Re}_{c}^{2}+H \mathrm{Re}_{c}^{3}\right) J_{r}^{*} \\
& +\left(I+J \mathrm{Re}_{c}+K \mathrm{Re}_{c}^{2}+L \mathrm{Re}_{c}^{3}\right) J_{r}^{* 2}+\left(M+N \mathrm{Re}_{c}+O \mathrm{Re}_{c}^{2}+P \mathrm{Re}_{c}^{3}\right) J_{r}^{* 3}
\end{aligned}
$$

In the previous equation, $J_{r}^{*}$ is calculated by Equation (9). Comparing both graphics, the original and that one obtained by Equation (10), it is observed as maximum error 3.8\%.

\subsection{Correction Factor by Uneven Baffle Spacing at the Inlet and/or Outlet, $J_{s}$}

This factor has an effect when exist a different baffle distribution at the inlet and/or outlet and along the tube bundle and it is computed by Equation (11):

$$
J_{s}=\frac{\left(N_{b}-1\right)+\left(l_{s, I}^{*}\right)^{1-n^{n}}+\left(l_{s, o}^{*}\right)^{1-n^{\prime \prime}}}{\left(N_{b}-1\right)+l_{s, I}^{*}+l_{s, o}^{*}}
$$

where $n^{\prime \prime}=0.6$ for turbulent flow and $\left(\operatorname{Re}_{c}>100\right)$.

$n^{\prime \prime}=1 / 3$ for laminar flow and $\left(\operatorname{Re}_{c}<100\right)$.

\subsection{Correction Factor by Friction of an Ideal Bank Tubes $f_{i}$}

The correction factor by friction in a triangular and rotated square set is determined in function of $\operatorname{Re}_{c}$ and the constants presented in Table 7 by the Equation (12).

$$
\begin{aligned}
f_{i}= & \exp \left\{\mathrm{A}+\mathrm{B} \ln \left(\mathrm{Re}_{c}\right)+\mathrm{C} \ln \left(\mathrm{Re}_{c}\right)^{2}+\mathrm{D} \ln \left(\mathrm{Re}_{c}\right)^{3}+\mathrm{E} \ln \left(\mathrm{Re}_{c}\right)^{4}+\mathrm{F} \ln \left(\mathrm{Re}_{c}\right)^{5}\right. \\
& \left.+\mathrm{G} \ln \left(\mathrm{Re}_{c}\right)^{6}+\mathrm{H} \ln \left(\mathrm{Re}_{c}\right)^{7}+\mathrm{I} \ln \left(\mathrm{Re}_{c}\right)^{8}+\mathrm{J} \ln \left(\mathrm{Re}_{c}\right)^{9}\right\}
\end{aligned}
$$

A maximum error of $4.9 \%$ is result of comparing the original graph to that one obtained by Equation (12).

\subsection{Pressure Loss Correction Factor by Tube-Baffle Leakage $\boldsymbol{R}_{l}$}

The introduction of this correction factor is due to the leakage of the tube bundle and it is computed by Equation (13) which is in terms of $S_{1}=S_{s b} /\left(S_{s b}+S_{t b}\right)$ and $S_{2}=\left(S_{s b}+S_{t b}\right) / S_{m}$.

$$
\begin{aligned}
R_{l}= & {\left[\mathrm{A}+\mathrm{B}\left(S_{1}\right)+\mathrm{C}\left(S_{1}\right)^{2}+\mathrm{D}\left(S_{1}\right)^{3}\right]+\left[\mathrm{E}+\mathrm{F}\left(S_{1}\right)+\mathrm{G}\left(S_{1}\right)^{2}+\mathrm{H}\left(S_{1}\right)^{3}\right] S_{2} } \\
& +\left[\mathrm{I}+\mathrm{J}\left(S_{1}\right)+\mathrm{K}\left(S_{1}\right)^{2}+\mathrm{L}\left(S_{1}\right)^{3}\right]\left(S_{2}\right)^{2}+\left[\mathrm{M}+\mathrm{N}\left(S_{1}\right)+\mathrm{O}\left(S_{1}\right)^{2}+\mathrm{P}\left(S_{1}\right)^{3}\right]\left(S_{2}\right)^{3}
\end{aligned}
$$

\begin{tabular}{|c|c|c|c|c|c|c|c|}
\hline \multicolumn{3}{|c|}{ Type arrangement, outside diameter and pitch between tubes } & \multirow{2}{*}{ A } & \multirow{2}{*}{ B } & \multirow{2}{*}{$\mathrm{C}$} & \multirow{2}{*}{$\mathrm{D}$} & \multirow[b]{2}{*}{$\mathrm{E}$} \\
\hline Arrangement & Diameter & Pitch & & & & & \\
\hline Triangular & $19.05 \mathrm{~mm}$ & $23.8125 \mathrm{~mm}$ & 4.15076 & -0.675323 & -0.254615 & 0.0590471 & -0.00431448 \\
\hline Triangular & $25.4 \mathrm{~mm}$ & $31.75 \mathrm{~mm}$ & 4.15076 & -0.675323 & -0.254615 & 0.0590471 & -0.00431448 \\
\hline Rhombic & $19.05 \mathrm{~mm}$ & $25.4 \mathrm{~mm}$ & 3.69311 & -1.18662 & 0.281179 & -0.136488 & 0.0280708 \\
\hline Triangular & $19.05 \mathrm{~mm}$ & $25.4 \mathrm{~mm}$ & 3.85004 & -0.609235 & -0.278939 & 0.0630913 & -0.00452036 \\
\hline Rhombic & $25.4 \mathrm{~mm}$ & $31.75 \mathrm{~mm}$ & 3.97656 & -0.796179 & -0.1565 & 0.0319655 & -0.00143937 \\
\hline Square & $19.05 \mathrm{~mm}$ & $25.4 \mathrm{~mm}$ & 3.76203 & -0.9323 & -0.0827537 & 0.0678788 & -0.0281861 \\
\hline Square & $25.4 \mathrm{~mm}$ & $31.75 \mathrm{~mm}$ & 3.99352 & 0.768721 & -0.32634 & 0.176985 & -0.0326325 \\
\hline \multicolumn{3}{|c|}{ Type arrangement, outside diameter and pitch between tubes } & \multirow{2}{*}{$\mathrm{F}$} & \multirow{2}{*}{ G } & \multirow{2}{*}{$\mathrm{H}$} & \multirow{2}{*}{ I } & \multirow{2}{*}{$\mathrm{J}$} \\
\hline Arrangement & Diameter & Pitch & & & & & \\
\hline Triangular & $19.05 \mathrm{~mm}$ & $23.8125 \mathrm{~mm}$ & 0.000102933 & 0 & 0 & 0 & 0 \\
\hline Triangular & $25.4 \mathrm{~mm}$ & 31.75 mm & 0.000102933 & 0 & 0 & 0 & 0 \\
\hline Rhombic & $19.05 \mathrm{~mm}$ & $25.4 \mathrm{~mm}$ & -0.00237654 & 0.0000713989 & 0 & 0 & 0 \\
\hline Triangular & $19.05 \mathrm{~mm}$ & $25.4 \mathrm{~mm}$ & 0.000103903 & 0 & 0 & 0 & 0 \\
\hline Rhombic & $25.4 \mathrm{~mm}$ & $31.75 \mathrm{~mm}$ & 0.00547024 & -0.000459287 & 0.000013822 & 0 & 0 \\
\hline Square & $19.05 \mathrm{~mm}$ & 25.4 mm & -0.00409219 & 0.00245958 & 0.0003604 & 0.000022754 & $-5.37988 \times 10^{-7}$ \\
\hline
\end{tabular}

The constants required by the equations are established in Table 8. Comparing the original graph and that one obtained by Equation (13) is observed a maximum error of $4.5 \%$.

Table 7. Constants for the equation for the correction factor $f_{i}$. 
Table 8. Constants for the equation for the correction factor $R_{l}$.

\begin{tabular}{ccccccccc} 
Values of $S_{1}$ & $\mathrm{~A}$ & $\mathrm{~B}$ & $\mathrm{C}$ & $\mathrm{D}$ & $\mathrm{E}$ & $\mathrm{F}$ & $\mathrm{G}$ & $\mathrm{H}$ \\
\hline 0 to 0.3 & 0.9930511 & 0.04163241 & -0.07862612 & 0.01413662 & -4.092978 & -6.546514 & 4.516072 & -2.525205 \\
0.3 to 0.8 & 0.7499537 & -0.4381533 & 0.2981431 & 0.1471556 & -0.709333 & 0.0847061 & 1.053554 & -4.215857 \\
\hline Values of $S_{1}$ & $\mathrm{I}$ & $\mathrm{J}$ & $\mathrm{K}$ & $\mathrm{L}$ & $\mathrm{M}$ & $\mathrm{N}$ & $\mathrm{O}$ & $\mathrm{P}$ \\
\hline 0 to 0.3 & 15.6087 & 30.3289 & -23.86598 & 14.08358 & -23.22663 & -41.67332 & 24.92778 & -15.50438 \\
0.3 to 0.8 & 0.3060496 & 1.27137 & -12.85256 & 19.67211 & -0.212271 & -3.186438 & 18.491314 & -23.16708 \\
\hline
\end{tabular}

\subsection{Pressure Loss Correction Factor by Recirculation Effect $R_{b}$}

This correction factor is provoked by circulation currents in the heat exchanger and it is computed by Equation (14) which is in terms of $F_{s b p}$ and $N_{2}=N_{s s} / N_{c}$.

$$
\begin{aligned}
R_{b}= & {\left[\mathrm{A}+\mathrm{B}\left(N_{2}\right)+\mathrm{C}\left(N_{2}\right)^{2}+\mathrm{D}\left(N_{2}\right)^{3}+\mathrm{E}\left(N_{2}\right)^{4}\right]+\left[\mathrm{F}+\mathrm{G}\left(N_{2}\right)+\mathrm{H}\left(N_{2}\right)^{2}+\mathrm{I}\left(N_{2}\right)^{3}+\mathrm{J}\left(N_{2}\right)^{4}\right] F_{s b p} } \\
& +\left[\mathrm{K}+\mathrm{L}\left(N_{2}\right)+\mathrm{M}\left(N_{2}\right)^{2}+\mathrm{N}\left(N_{2}\right)^{3}+\tilde{\mathrm{N}}\left(N_{2}\right)^{4}\right] F_{s b p}^{2}+\left[\mathrm{O}+\mathrm{P}\left(N_{2}\right)+\mathrm{Q}\left(N_{2}\right)^{2}+\mathrm{R}\left(N_{2}\right)^{3}+\mathrm{S}\left(N_{2}\right)^{4}\right] F_{s b p}^{3} \\
& +\left[\mathrm{T}+\mathrm{U}\left(N_{2}\right)+\mathrm{V}\left(N_{2}\right)^{2}+\mathrm{W}\left(N_{2}\right)^{3}+\mathrm{X}\left(N_{2}\right)^{4}\right] F_{s b p}^{4}
\end{aligned}
$$

The constants demanded by the equation are defined in Table 9 and they are in terms of $\mathrm{Re}_{c}$ number. Comparing the original graph and that one obtained by Equation (14), the maximal error found is $1.3 \%$.

\subsection{Pressure Loss Correction Factor by Uneven Baffle Spacing at the Inlet and Outlet}

This correction factor is proposed by the uneven baffle spacing at inlet and outlet of the heat exchanger and this factor is calculated by Equation (15).

$$
R_{s}=\frac{1}{2}\left[\left(l_{s, I}^{*}\right)^{-n^{\prime}}+\left(l_{s, o}^{*}\right)^{-n^{\prime}}\right]
$$

where $n^{\prime}=1.6$ for turbulent flow $\left(\operatorname{Re}_{c}>100\right)$.

$n^{\prime}=1$ for laminar flow $\left(\operatorname{Re}_{c}<100\right)$.

\section{Calculus Program}

Having the correction factors in an analytical form, it was developed a calculus program using the FORTRAN 77 language which will design quickly the shell and tubes heat exchanger through the improvement DELAWARE Method. This computing program is described next:

\section{Flow Chart Program}

The flow chart used for the shell and tubes heat exchanger is presented in Figure 2.

As from this flow chart, it was made the heat exchanger design program using the executable BELL since it runs in MS DOS platform.

\section{Conclusions}

This work has presented the improvements to the Delaware method for the shell and tube heat exchanger design. These improvements were made up not only of obtaining the correction factor equations which were only available in graphic forma but also of developing the computing program in Fortran 77 language.

Thus, a new and easy tool for the shell and tubes heat exchanger design is available which allows accomplishing the numerical computing in a quick form minimizing the errors of the graphical lecture. This system gives the opportunity to explore different design alternatives in order to find the optimal solution to each proposed problem.

Recent years, heat exchanger is often used for the request of technology. But the relevant design is not provided by the actual standards. This work presents the improvements to the Delaware method for the shell and 
Table 9. Constants for the equation for the correction factor $R_{b}$.

\begin{tabular}{cccccccccc}
\hline For & $\mathrm{A}$ & $\mathrm{B}$ & $\mathrm{C}$ & $\mathrm{D}$ & $\mathrm{E}$ & $\mathrm{F}$ & $\mathrm{G}$ & $\mathrm{H}$ \\
\hline $\mathrm{Re}_{c}>100$ & 0.9999956 & 0.02427714 & -0.2498571 & 0.87688954 & -0.9389413 & -3.7854133 & 42.7281376 & -285.42201 & 841.836875 \\
$\mathrm{Re}_{c}<100$ & 0.9989929 & 0.10536115 & -0.8164392 & 2.13589149 & -1.8323906 & -4.7393642 & 60.6001915 & -402.43318 & 1138.26259 \\
\hline For & $\mathrm{J}$ & $\mathrm{K}$ & $\mathrm{L}$ & $\mathrm{M}$ & $\mathrm{N}$ & $\mathrm{N}$ & $\mathrm{O}$ & $\mathrm{P}$ & $\mathrm{Q}$ \\
\hline $\mathrm{Re}_{c}>100$ & -823.25082 & 6.9400004 & -114.27156 & 831.289197 & -2493.3366 & 2464.67857 & -7.1165478 & 129.6448 & -995.82525 \\
$\mathrm{Re}_{c}<100$ & -1075.7794 & 11.8151337 & -238.94173 & 1739.20139 & -4979.2121 & 4724.16651 & -17.614757 & 423.093405 & -3227.2538 \\
\hline For & $\mathrm{R}$ & $\mathrm{S}$ & $\mathrm{T}$ & $\mathrm{U}$ & $\mathrm{V}$ & $\mathrm{W}$ & $\mathrm{X}$ & \\
\hline $\mathrm{Re}_{c}>100$ & 3071.9304 & -3083.9014 & 3.21390213 & -60.119316 & 480.616728 & -1521.5693 & 1550.23124 \\
$\mathrm{Re}_{c}<100$ & 9354.34611 & -8902.6809 & 11.6766845 & -302.46692 & 2376.53333 & -6980.2925 & 6687.42629 \\
\hline
\end{tabular}

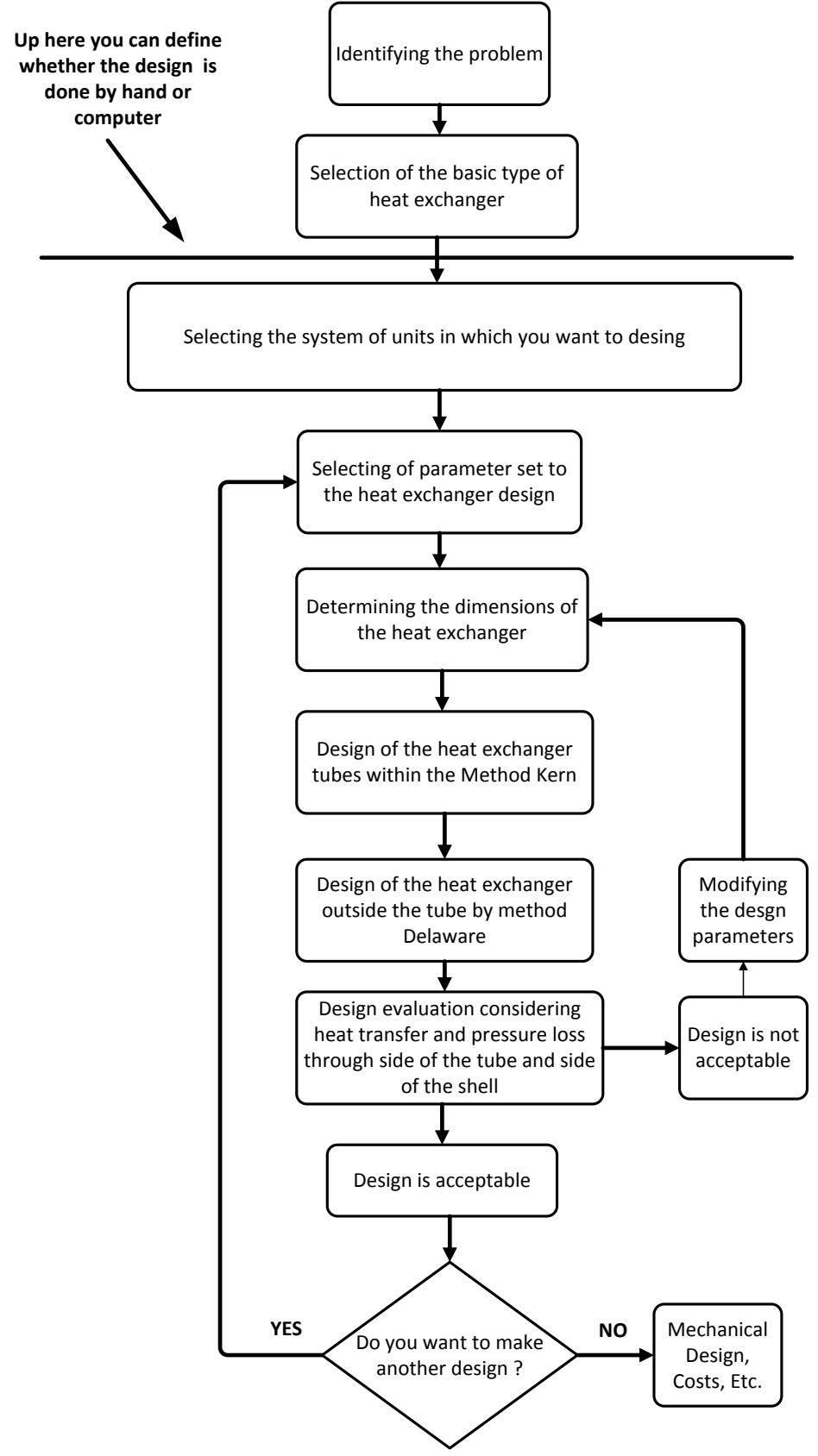

Figure 2. Flow chart program. 
tube heat exchanger design.

\section{References}

[1] Vengateson, U. (2010) Design of Multiple Shell and Tube Heat Exchangers in Series: E Shell and F Shell. Chemical Engineering Research and Design, 88, 725-736. http://dx.doi.org/10.1016/j.cherd.2009.10.005

[2] Costa, A.L.H. and Queiroz, E.M. (2008) Design Optimization of Shell and tube Heat Exchangers. Applied Thermal Engineering, 28, 1798-1805. http://dx.doi.org/10.1016/j.applthermaleng.2007.11.009

[3] Serna, M. and Jimenez, A. (2005) A Compact Formulation of Bell-Delaware Method for Heat Exchanger Desing and Optimation. Chemical Engineering Research and Desing, 83, 539-550. http://dx.doi.org/10.1205/cherd.03192

[4] Shah, R.K., Dusan, P. and Sekulic, D.P. (2003) Fundamentals of Heat Exchanger Design. John Wiley \& Sons, Hoboken. http://dx.doi.org/10.1002/9780470172605

[5] Ayub, Z.H. (2005) A New Chart Method for Evaluating Single-Phase Shell Side Heat Transfer Coefficient in a Single Segmental Shell and Tube Heat Exchanger. Applied Thermal Engineering, 25, 2412-2420. http://dx.doi.org/10.1016/j.applthermaleng.2004.12.015

[6] Leong, K.C., Toh, K.C. and Leong, Y.C. (1998) Shell and Tube Heat Exchanger Design Software for Educational Applications. International Journal of Engineering Education, 14, 217-224

[7] León, A.R., Velazquez, M.T. and Diez, P.Q. (2011) The Design of Heat Exchangers. Engineering, 3, 911-920.

[8] Castillo, R. (1999) Diseño Computacional de Intercambiadores de Calor de Coraza y Tubos por el Método Delaware. Tesis de Maestría, Instituto Politécnico Nacional, México. 


\section{Nomenclature}

\begin{tabular}{|c|c|}
\hline$\rho_{c}$ & Fluid density. \\
\hline$\mu_{\mathrm{c}}$ & Average fluid viscosity. \\
\hline$\Delta P_{b, i}$ & Pressure loss in a cross-flow section. \\
\hline$\Delta P_{c}$ & Total pressure loss on the side of the shell. \\
\hline$\Delta P_{w, i}$ & Pressure loss in a window section. \\
\hline$\mu_{w c}$ & Fluid Viscosity wall temperature. \\
\hline$A$ & Heat transfer area. \\
\hline$C p_{c}$ & Specific heat. \\
\hline$e_{t}$ & Tube thickness. \\
\hline$F_{c}$ & Total fraction of tubes in cross flow. \\
\hline$F$ & Correction factor heat exchanger configuration. \\
\hline$f_{i}$ & Correction factor due to friction. \\
\hline$F_{s b p}$ & Fraction cross flow area available for recirculation flow. \\
\hline$g$ & Acceleration of gravity. \\
\hline$h_{c c}$ & Fluid convection coefficient outside the tubes. \\
\hline$h_{\text {io }}$ & Convection coefficient of the fluid by the tube side. \\
\hline$J_{r}^{*}$ & Basic correction factor for adverse effect of the temperature gradient. \\
\hline$J_{b}$ & Correction factor recirculation effect. \\
\hline$J_{c}$ & Effect correction factor baffle configuration. \\
\hline$J_{i}$ & Correction factor due to friction. \\
\hline$J_{l}$ & Correction factor for leakage effect. \\
\hline$J_{r}$ & Correction factor adverse effect of the temperature gradient. \\
\hline$J_{s}$ & Correction factor for baffle uneven spacing effect on entry and exit. \\
\hline$k$ & Thermal conductivity of the tube material. \\
\hline$k_{c}$ & Thermal conductivity of the fluid. \\
\hline \multicolumn{2}{|c|}{$l_{s, o}^{*}=l_{s, I}^{*}=l_{s, o} / l_{s}=l_{s, I} / l_{s}$} \\
\hline$l_{s}$ & Spacing between baffles. \\
\hline$l_{s, I}, l_{s, o}$ & Spacing of baffles at the entrance and exit. \\
\hline$N_{b}$ & Number of baffles. \\
\hline$N_{c}$ & Number of rows in cross flow section. \\
\hline$N_{c w}$ & Number of rows in section window. \\
\hline$N_{s s}$ & Numbers Stamp/sides sealed. \\
\hline$N_{t}$ & Number of tubes. \\
\hline$Q$ & Heat flux exchanged. \\
\hline$R_{b}$ & Correction factor recirculation effect. \\
\hline$R_{d}$ & Total coefficient of fouling. \\
\hline $\operatorname{Re}_{c}$ & Reynolds number. \\
\hline$R_{l}$ & Correction factor for leakage effect. \\
\hline$R_{\mathrm{s}}$ & Correction factor adverse effect of the temperature gradient. \\
\hline$S_{s b}$ & Correction factor for baffle uneven spacing effect on entry and exit. \\
\hline$S_{t b}$ & Thermal conductivity of the tube material. \\
\hline$T_{m l c}$ & Thermal conductivity of the fluid. \\
\hline$U_{d c}$ & Spacing between baffles. \\
\hline$W_{c}$ & Spacing of baffles at the entrance and exit. \\
\hline
\end{tabular}

